\title{
25 \\ INFORMATION SYSTEMS RESEARCH AND DEVELOPMENT BY ACTIVITY ANALYSIS AND DEVELOPMENT: Dead Horse or the Next Wave?
}

\author{
Mikko Korpela \\ University of Kuopio
}

Anja Mursu

University of Kuopio

\author{
Abimbola Soriyan \\ Obafemi Awolowo University
}

Anne Eerola

University of Kuopio

Heidi Häkkinen

University of Kuopio

Marika Toivanen

University of Kuоpio

\begin{abstract}
We argue that the currently dominant methods in Information Systems are not satisfactory for emancipatory research and development whose starting point is work. Activity theory was proposed as such an emancipatory research-cumdevelopment approach in IS a decade ago. However, the potential identified in the theory has not fully materialized. As our own contribution toward making activity theory more operational in IS, we present an elaborated framework, Act AD, and review our experience in applying it to descriptive research, practical analysis, and constructive research. We claim that in order to fully unleash the potential of activity theory, activity-based methods should be developed further for IS requirements analysis projects and IS implementation projects, as well as for facilitating software development. The most appropriate way of developing such applied methods is through collaborative action
\end{abstract}


research in real-life information systems work-the information systems practitioners developing their own work through activity analysis and development, with researcher participation.

Keywords: Activity theory, emancipatory research, work development, information systems development, methodology

\section{INTRODUCTION: WORK IS THE KEY}

Ever since the Manchester conference on Information Systems research methods in 1984, the international research community has recognized that a diversity of research approaches or philosophies exists within IS. According to Orlikowski and Baroudi (1991), three broad categories are commonly identified: positivist, interpretive, and critical. In this paper, we take the last mentioned, emancipatory or developmental standpoint (i.e., we are not only interested in understanding information systems within organizations, but also in developing "better" information systems). What, then, does better mean? What criteria should good information systems meet?

Different theorists in different times have named different factors as the most important, distinctive aspects of information systems. The very term information system implies that information is what it all comes down to. Those who share this view delve into information flows and entity-relationship models, regardless of the technology and purpose of information processing. Others underline technology, usually equating it with computers, and particularly equating information systems with software systems. Those with cybernetic backgrounds emphasize the term system, searching only for systemic entities and ignoring how bits and pieces of information and communication technology (ICT) are used in organizations. Researchers applying Habermas stress the communication aspects ofinformation systems, viewing them as language games. In the very title of IFIP WG 8.2, social and organizational aspects of information systems are emphasized, with the view that the term information system refers to the organizational processes and resources of information management. Finally, the human or individual actors of information systems are pointed out as the starting point much too seldom.

In our mind, all these aspects-information, technology, system, communication, organization and the individual-are important factors, but still only elements. None of these viewpoints sufficiently explains the purpose for which information systems exist.

Our starting point is that purposeful work is the proper holistic viewpoint that binds the elements together. Individuals in organizations need information, use technology, and communicate, in more or less systemic ways, to jointly produce some services or products (use-values). An improved information system in this viewpoint means better facilitation to the workers to do their work. This can be achieved by means of better information, by means of more efficient technology, by means of better organization, by means of more humane work conditions, etc.

What kind of methodologies are available in current literature for IS research and practice whose starting point is work with an emancipatory and developmental approach? In this conference, the pioneering and foundations laying role of the socio- 
technical approach, soft systems methodology and the so-called Scandinavian school since the Manchester 1984 conference is self-evident. Considering the recent IFIP WG 8.2 conferences, however, two theoretical frameworks dominate: actor-network theory (Walsham 1997) and structuration theory (Walsham and Han 1991). The former is commonly regarded as tedious, the latter as over-general, and neither of them pays much attention to work practice. Both of them are only research methodologies, and not very easily transformed into practical information systems development methodologies.

Ethnomethodology and other ethnographic research methods in IS (Myers 1999) do pay attention to work practice, but they are better suited to descriptive analysis than developmental or design purposes. Moreover, ethnomethodology does not provide a theoretical basis for understanding work.

Alter $(1999,2001,2002)$ has suggested the work system method as an approach for understanding and analyzing systems in organizations whether or not information technology (IT) plays an essential role. In Alter's words,

a work system is a system in which human participants and/or machines perform business processes using information, technologies, and other resources to produce products and/or services for internal or external customers.

While Alter's approach fits well with our objectives by starting from purposeful work as the systemic unit of contextualized analysis, his framework is not based on established social theory of work.

Regarding methods for information systems practice, participatory design (Kensing and Blomberg 1998) provides diverse experiences and methods for emancipatory information system development, but with little or no theoretical foundation. In software engineering, Robertson and Robertson (1999) provide a requirements analysis and design methodology with a rare, explicit starting point in work analysis, but narrow down its scope only to process chains and software design.

Something more operational than actor-network theory and structuration theory but more theoretically founded than participatory design, ethnomethodology, or work system method is needed. In this paper we study the applicability of activity theory as a methodology for work-oriented IS research and development, and present experiences in applying an elaborated activity-theoretical framework.

\section{ACTIVITY THEORY IN INFORMATION SYSTEMS}

Activity theory has a broad and long research tradition, which emphasizes that human activity is culturally and historically formed, mediated, and defined by its object. It is beyond the scope of this paper to provide a tutorial on the evolution of activity theory since the 1920s; Hedegaard et al. (1999) provide a concise introduction. There are several widely different traditions within activity theory, but the activity-theoretical framework most commonly applied in Information Systems is developmental work research (DWR) developed by Engeström (1987, 1999).

Activity theory was first presented as an IS research approach in the IFIP WG 8.2 conference in Copenhagen that followed the first Manchester conference on research methods. Kuutti (1991) suggested, in line with the standpoint of this paper, that the very 
object of analysis in IS should be activity system instead of information system. Similarly, Bødker (1991) discussed the potential of activity theory as an analytical framework in understanding computer-based artefacts as instruments for work activities and materials for systems design.

During the decade after the Copenhagen conference, activity theory has been applied to research in the fields of human-computer interaction, computer-supported cooperative work, and information systems in a few studies (Bardram 2000; Bertelsen and Bødker 2000; Bødker 1997; Mwanza 2002; Redmiles 2002; Vrazalic and Gould 2001). Some research tradition can be found in Aarhus, Denmark, in Ronneby, Sweden, in Oulu, Finland, as well as in smaller groups in the United States, Australia, and New Zealand.

In Finland, dozens of developmental work research projects have been conducted, and many of them have involved information technology and information systems in some way. However, IS researchers have not been involved in these projects, so the methods have not been developed toward improved applicability to IS. Furthermore, very little has been published in English on the methodological development in these projects. There is no coherent textbook or methodological guide available for the international audience on DWR (e.g., regarding the formalized heavy work development method called Change Laboratory). Thus, the DWR experience in Finland has not enriched the IS research and development methods.

Activity theory in general and Engeström's developmental work research in particular emphasize that activity is a collective phenomenon involving several actors. The studies reviewed above, however, tend to reduce activity into a set of actions by an individual-the doctor's activity, the patient's activity, etc. The analytical model does not guide the researcher clearly enough into studying the individual and collective aspects of work activities within the same framework. This leads to a relatively weak support of designers of cooperative systems.

Activity theory has not been applied in IS as much as was expected in the early 1990s (livari and Lyytinen 1998), Is it a dead horse, gone with the wind, or can it be revived within IS?

In our mind, an analytical framework for emancipatory, work-oriented IS research and practice should meet the following requirements:

1. The starting point must be work activity as a systemic entity.

2. Technology, including computer-based technology, must be seen as a tool to facilitate work, embedded in the work system.

3. Both collective and individual aspects of work need to be taken into account.

4. Work systems need to be studied in their organizational context.

5. The analytical framework must be based on a sound theoretical basis.

6. The analytical framework must be applicable to both descriptive studies and practical development.

7. The analytical framework must be applicable both to technological development by software and IS professionals and to the developing of the work practice itself by the workers.

Activity theory provides a good starting point for developing a framework that satisfies these requirements and for methodologies that make use of the framework. 
Activity theory and DWR are, however, very generic approaches that need to be adapted before they can be feasibly used by IS researchers and practitioners. As long as such adaptations of activity theory are not available, it will not spread in IS research and practice.

Our research group has for several years elaborated on an activity analysis and development framework, Act AD, that could be adapted to information systems research and practice. While accepting all of the fundamental aspects of Engeström's model, we aimed at making it more operational.

\section{ACTIVITY ANALYSIS AND DEVELOPMENT}

In this section we present a brief summary of the ActAD framework (originally published in Mursu et al., 2003; for more detailed accounts, see Korpela et al. 2000, 2002a, 2002b). In section 4 we present experiences in using the framework as a tool in analyzing and developing information systems.

Let us first illustrate our concepts with an example from intensive care in a hospital. In order to bring a seriously ill baby back to normal life, several healthcare professionals obviously need to engage in a care process and take action within it (Figure 1). The poor health of the baby is the object of the activity in this case, and the improvement of her health condition is the intended outcome, which is the purpose the of activity.

Looking closer into the process of the activity, in Figure 2 we have two of the actors (nurses) required in the care process engaged in actions, making use of different means ofaction (both physical and mental). In order to achieve the intended outcome, it is important that the individual actions are coordinated toward the shared goal. Various means of coordination and communication are employed to that end; in this case, a vital signs monitor helps the nurses to coordinate their actions.

When the health condition of the baby has improved sufficiently, the intensive care activity is completed and the responsibility of her further care is handed over to an ordinary ward (Figure 3). The outcome of the intensive care activity transforms into the object of the ward activity. A third type of means, means of networking, is required to mediate the relation between the activities. In this case, patient documents are such a means.

The concepts introduced in the intensive care case in an informal manner are now presented as an abstract framework (Figure 4). The framework starts from the elements of a mediated action by an individual person (Figure 4, broken line); the subject or actor, the object of the action, the instruments or means (both mental and physical) needed for the action, as well as the goal (Vygotsky 1978). For instance, a carpenter uses a hammer and applies his skills to some planks and nails in order to construct a scaffolding for a building.

In practice it almost always takes several actions by several individuals to produce any useful service or product (Figure 4, lower half); for instance, a number of carpenters, bricklayers, and electrical workers are needed to build a house. In activity theory, such a set of mediated actions on a shared object by a number of actors, directed by a (more or less consciously)jointly aspired outcome, is called an activity (Leontiev, 1978). It is important to notice that individual human actions can only be understood through the collective activity of which they are a part. Instead of bunches of uncoordinated actions, work, in practice, consists of systemic activities subordinating the actions in a purposeful way. 


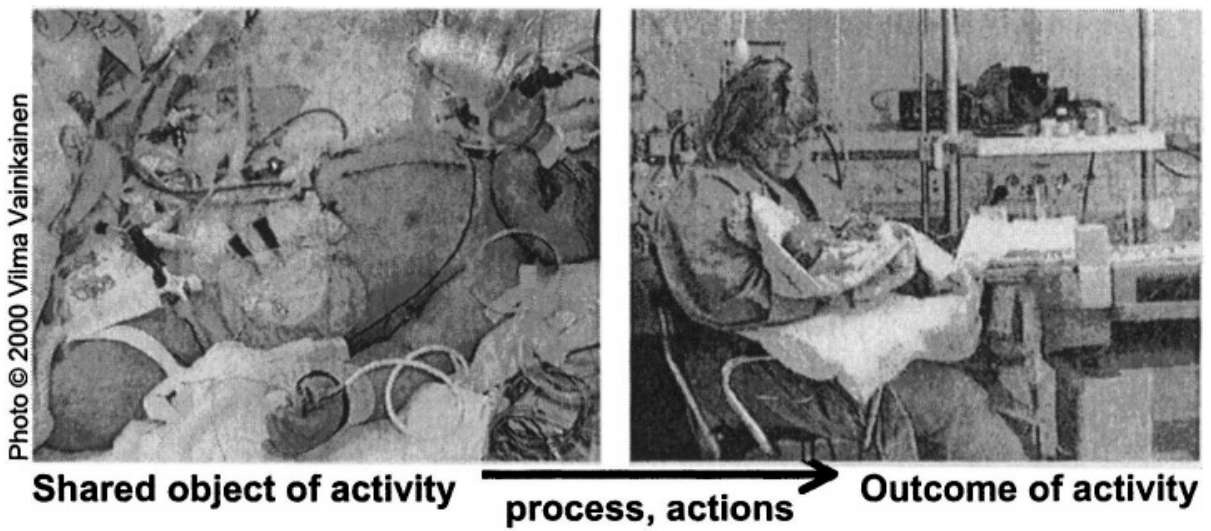

Figure 1. The Object and Intended Outcome of an Activity;

Neonatal Intensive Care as the Case

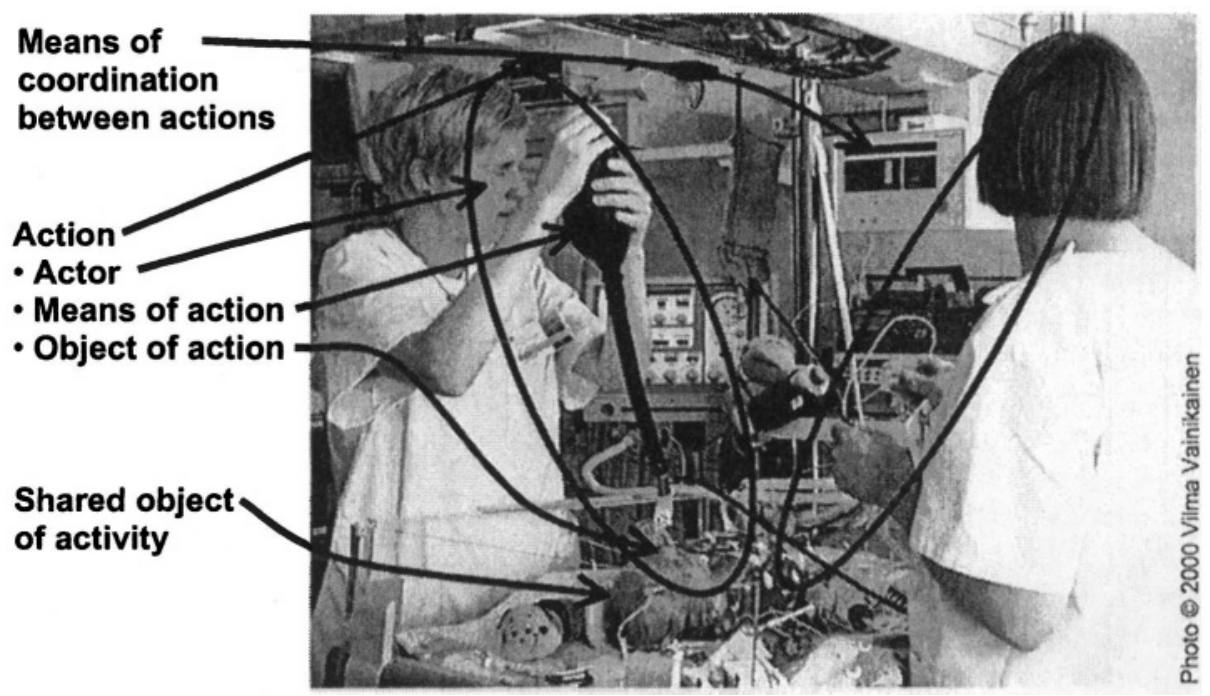

Figure 2. Two Actors Performing Actions That Are Part of the Activity, with Two Types of Means 


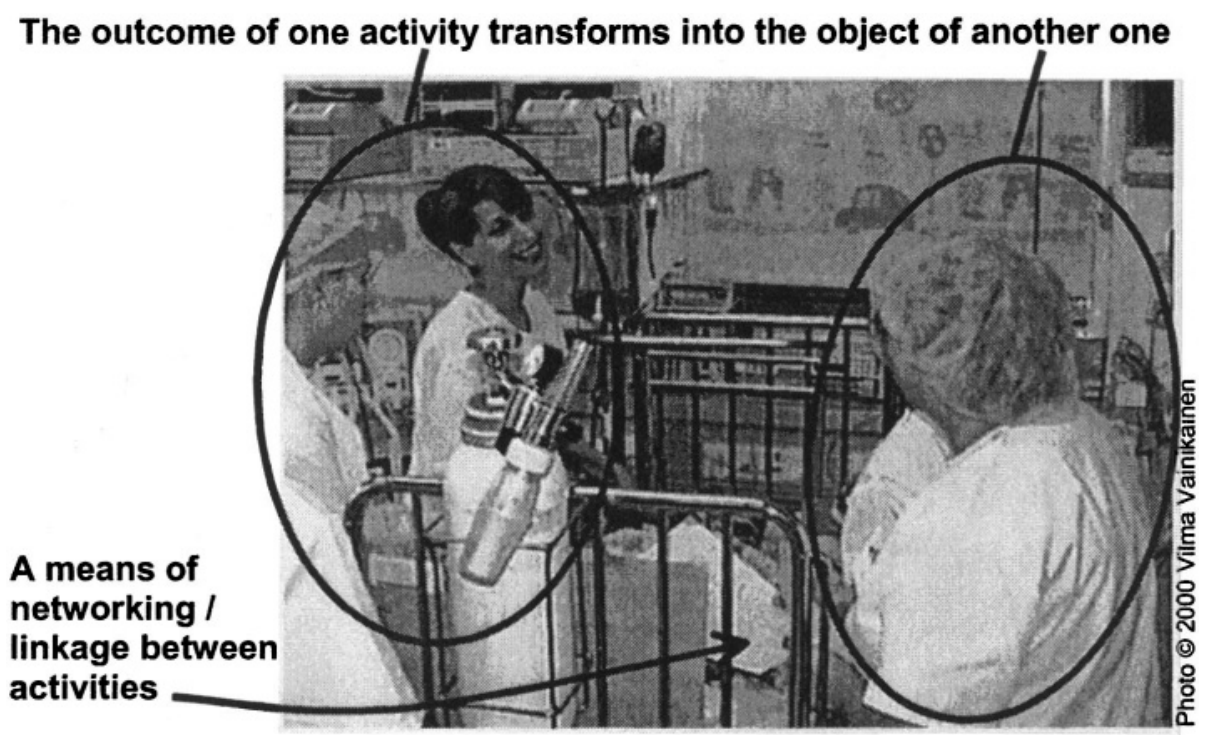

Figure 3. Intensive Care Activity Handing over to a Ward Activity

In addition to the instruments or means of the individual actions, other kinds of mediating instruments - social infrastructure - are also needed within an activity, as emphasized by Engeström (1987). The actions need to be oriented by means of coordination and communication (Figure 4, upper half); a blueprint, division of labor, meetings, and rules, for instance, among a construction team.

According to Engeström (1987), work activity as a real-world phenomenon is systemic by nature. That is, there must be a relative fit between the elements of a work activity, a mode of operation (Figure 4, large oval). When an activity evolves over time, it moves from one relative fit to another, from one mode to another, in historical phases. Today's house-building activity is quite different from what it was 20 or 100 years ago, both in terms of the elements (actors, object, and means) and in terms of the systemic mode of the activity. Contradictions, imbalance within and between various elements and the mode, are the force driving the activity to transform.

Finally, activities do not stand alone. The elements of one activity are produced by other activities, and the outcome of one activity is usually needed in one or more other activities (Figure 4, smaller ovals; Engeström, 1987). Construction workers do not cut and saw trees into planks on a building site any more, but buy planks sawn elsewhere in a sawmill activity. Mediation is also needed between the activities, and this is achieved by means of networking (Korpela et al., 2000). For instance, advertisement, contracts, and transportation are needed to link sawmill and house construction activities.

Networks of activities constitute the "metabolism of use-values" in society; i.e., activities are the "organs" that produce, exchange, and consume use-values in the "body" of society. The networks are split by organizational boundaries and accompanied by other kinds of societal relations (e.g., financial ones dealing with exchange values). Social theories other than activity theory should be applied to the organizational, financial, and wider societal contexts of activities (Korpela et al. 2001a). 


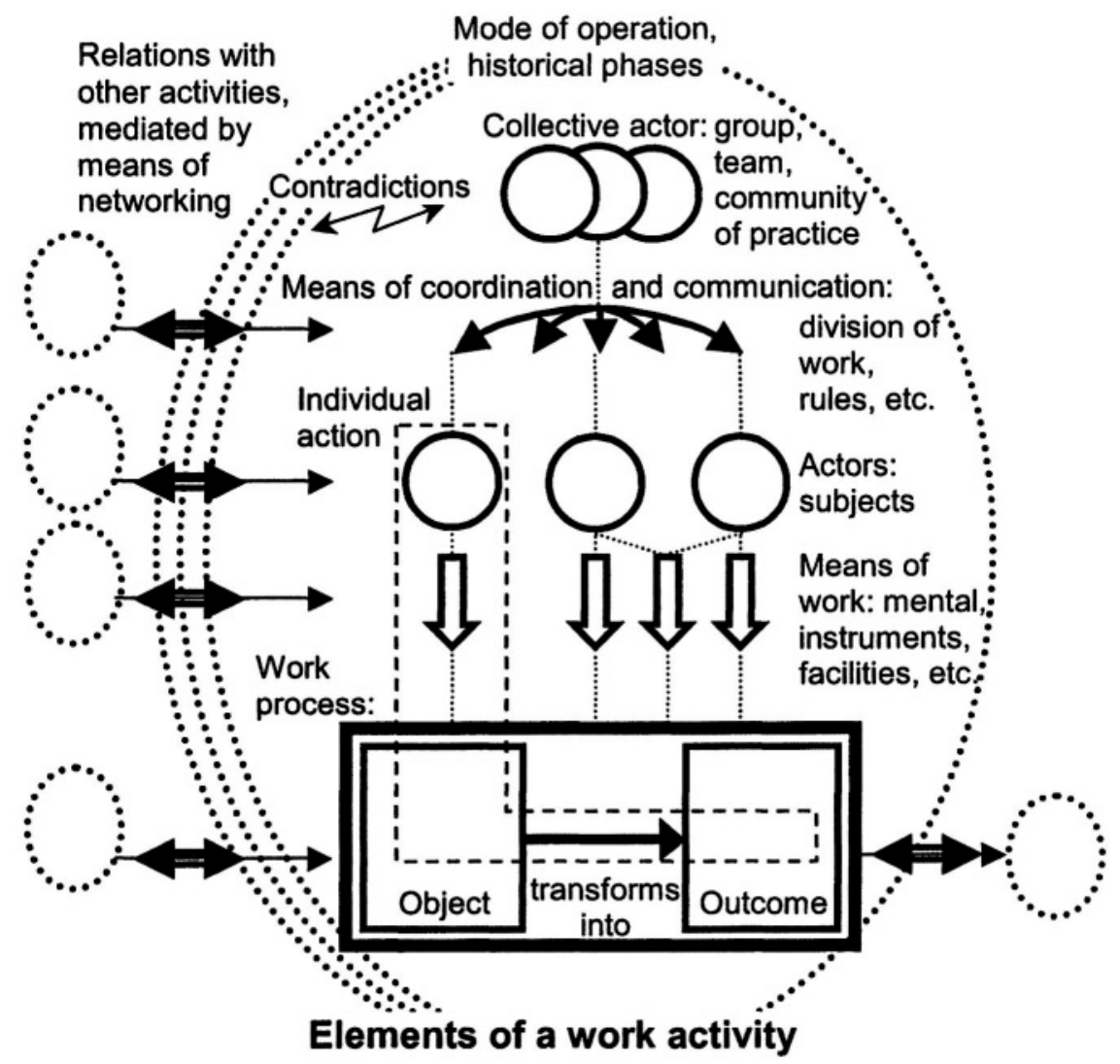

Figure 4. Three Different Types of Means in Activity Networks

(Mursu et al. 2003; Adapted from Korpela et al. 2000).

Compared with Engeström's original model, ActAD includes both individual actions and collective activity intertwined in the same model, emphasizes the systemic mode, generalizes the means of coordination and communication, and introduces the means of networking.

According to the model, ICT can be used as a means in three different ways: as a means of work in individual actions, as a means of coordination and communication between actions in an activity, and as a means of networking between activities. However, the scopes overlap. From the viewpoint of supporting work activities by ICT, all three types of means are needed.

Echoing Kuutti's voice from 1991, we maintain that the systemic unit that IS researchers and practitioners should consider first is (work) activity in all its aspects and dynamics. It is not very relevant whether or not the information management facilities and processes within an activity or a network form an information system; the point is whether the use of ICT facilitates the objectives of the activity. 
However, while ICT is becoming increasingly ubiquitous, it is one of the most important types of means in and between many information-laden activities. The need for new information-technological means is one of the most common sources for change in work, and information systems projects are one of the most common forms of change (Korpela et al. 2002a, 2002b).

\section{APPLICATION EXPERIENCES}

The proof of the pudding is in the eating. We have applied ActAD as an analytical framework in descriptive research, as lenses that enable students and laymen to better look at their own work, and as an explorative requirements analysis method in constructive research.

\subsection{Experiences in Descriptive Research}

In a joint Finnish-Nigerian project, where the main objective was to produce empirical evidence and understanding of the practice and problems of IS development in Nigeria, the software and information systems activities in three Nigerian software companies were analyzed using the ActAD framework (Mursu et al. 2002).

The framework, first illustrated by an imaginary IS project using cartoon-like figures, was used as an agenda in group discussions and interviews with Nigerian software practitioners. Afterward, the results of the interviews were presented to the informants using the same frameworks but the informants' own data. The interviewees grasped the model without any effort. The discussions remained mostly in a descriptive mood, but in a few situations the software professionals started to identify inadequacies in their own activities and to discuss potential remedies.

Due to the highly constrained circumstances and timescales, the discussions usually did not proceed to the prior historical phases of the activities. However, the ActAD framework provided a practicable tool for studying previously unknown activities, and the result was a rich picture-if only descriptive—of the information systems development activity in Nigeria (Mursu et al. 2002).

In the same project, Soriyan (2004) applied the framework to the analysis of 14 years of experience of a hospital software development project in an academic environment in Nigeria. The analysis dealt with the activity networks, organizational and international settings, as well as historical phases of the project. The analysis highlighted the role ofdifferent organizations' management activities and top managers, particularly when the project was to transform itself from in-house development to product development.

The descriptive studies of the Nigerian software development and information systems development also resulted in some preliminary normative guidelines, providing practitioners with methods for taking issues of sustainability and social impact into account in information systems implementation. These methods lean on the analysis of activity networks. The methods are, however, currently a work in progress.

The ActAD framework was tested and further developed during the FinnishNigerian project, in order to be suitable for IS research purposes. The interviewees 
grasped the framework without effort, and during the discussions they considered it as inspirational.

\subsection{Experiences with Analytical Lenses}

Good analytical theory should be like lenses that make us see our world brighter. In several small cases, we have provided the ActAD framework as a lens - as a checklist of key issues to look at - for laymen for a rapid analysis of their work, service, or activity chain.

The first experiment took place in Nigeria, where nurses and a general practitioner in a local health center were introduced to an early form of the ActAD framework by a couple of activity diagrams illustrated by cartoon-like figures (Korpela et al., 2000). They were then asked to analyze their own healthcare activities and activity networks using a list of questions based on the framework. The idea was to start identifying needs for improvement in the manual information system in their health center. The experiment worked surprisingly well; it was actually easier for the healthcare professionals to analyze their work than for local software academics to analyze the activity network around the manual information system.

The other experiences are from nine continuing education and Master's courses in Finland on information systems in healthcare and social services, starting from 1998. The students were nurses, social workers, medical doctors, and software practitioners. In some courses, the students were introduced to the ActAD framework during a onehour lecture. They were then asked to select a recent case when they had been involved in a patient-care activity, either as an actor or as an object (patient). The students were instructed to identify the object and the intended outcome, the actors required, and the different types of means. The task was to specifically discuss the role of the IT-based means and the possible needs for improvement in the information-technological facilitation of the activity. Especially revealing were the cases where the student had been an object of care; it was much more difficult for students in a healthcare professional's position to recognize what other actors actually did in the process and how the activity chain continued from one organization to another.

Multi-professional groups have used simple ActAD-based methods in four continuing education courses in conducting a developmental feasibility study. The methods applied are similar to the rapid assessment method described in the following section.

\subsection{Experiences in Constructive Research}

ActAD has been used for explorative analysis by two teams in a large software integration research and development project in Finland.

\subsubsection{Rapid Participatory Assessment Method for Integration Needs}

The first team developed a rapid participatory assessment method for integration needs, adapted from the training courses described above, using maternity care as the case setting (Häkkinen 2003). First, activities, networks, and formal organizations in the 
target domain are roughly identified. Major stakeholders within the activity network are then invited into two discussion sessions, no more than a couple of hours each. In the first session (critique workshop), the stakeholders elaborate on the details of the tentative description of the activity network and identify bottlenecks or problems. In the second session (abridged future workshop) the focus is on suggesting solutions-not only software integration but all types of solutions.

\subsubsection{Explorative Requirements Analysis Method}

The other team was given the task of developing methods for grasping a previously unexplored grey area of inter- and extra-organizational activities, in search of requirements for possible new software products or interfaces (Toivanen et al. 2003). Home care was selected as the case domain. Again, the explorative requirements analysis method developed by the team begins with developing a rough overview of the activities, networks, and organizations involved in order to identify major stakeholders. The number of social and healthcare professionals and other parties involved in providing home care services in this case study was astonishing.

Representatives of key stakeholder groups were then interviewed, using a semistructured interview guide that followed the activity framework but utilized terms specific to the home care domain instead of abstract terms such as actors or means. On the basis of the interviews, preliminary descriptions of the findings were collected and structured into documents and rich pictures on a wall. The findings were presented, considered, and processed forward with the stakeholders in workshops.

After the workshops, revised descriptions of the information needs in the network of activities were constructed. The outcome was depicted as a systematic description of the activity chains in the domain. Core activities were identified and described down to the level of actions, where the "empty spots" (lack of software) and requirements for new software and their integration with legacy systems can be identified. Using the acquired understanding, the purpose and the advantages of the would-be software and the first sketch for its architecture can be derived. The team has reached this stage by the time of writing this paper.

Software design today usually starts by describing use cases (i.e., the communication between human beings and software). In this case this was not possible because of the grey area; the inter- and extra-organizational activities were not sufficiently understood. Similarly to Robertson and Robertson (1999), we found it important to understand the work of the organizations and their personnel before proceeding to use case design. Furthermore, understanding the cooperation and communication between and inside organizations proved important.

Thus far the experiences have been promising. This method is significantly more laborious than the rapid assessment method, but correspondingly leads into a more detailed requirements description. The method gave us a lot of information needed for developing the work practices and the technological solutions, including "humanware," hardware, and software. However, in order to produce software specifications, our method needs further development. Next we will proceed from the descriptions of the key activities to describing the actions in which computer-based systems are required, and further to a software architecture and unified modeling language (UML; Fowler 2000) models. 
In conclusion, the explorative method proceeds from activity networks to software engineering.

1. Work is modeled as a network of activities within and between organizational boundaries, embracing all of the aspects of the ActAD framework presented in section 3 and Figure 4. In addition, clusters of information are emphasized as concepts of work and the relationships between them. This step is divided into three parts: gathering, structuring, and describing the information needs.

2. Using the results of the first step, more accurate functional and quality requirements of the intended software are designed. The key activities are described in more detail. The idea is that the process of an activity (how the object is transformed into the outcome through actions) is described in terms of the actions of various actors over time (see the generic sketch in Figure 5). A combination of the activity framework and UML's activity diagrams and use case diagrams are considered for this task (the term activity as used in UML has a completely different meaning than in activity theory). The purpose is to explore the information needs in more detail, and to identify empty spots for potential software; for instance, the needs for currently lacking computer-based means of action, coordination, or networking (applications or components). Simultaneously, the information system architecture and the first draft of the software architecture are defined. The software architecture specifies the software and its structure (i.e., components), relationships between new software and legacy systems, and its relationships with the environment. Finally, the software architecture is evaluated against the functional and quality requirements. If some further architectural evolution is required, step 2 is repeated accordingly.

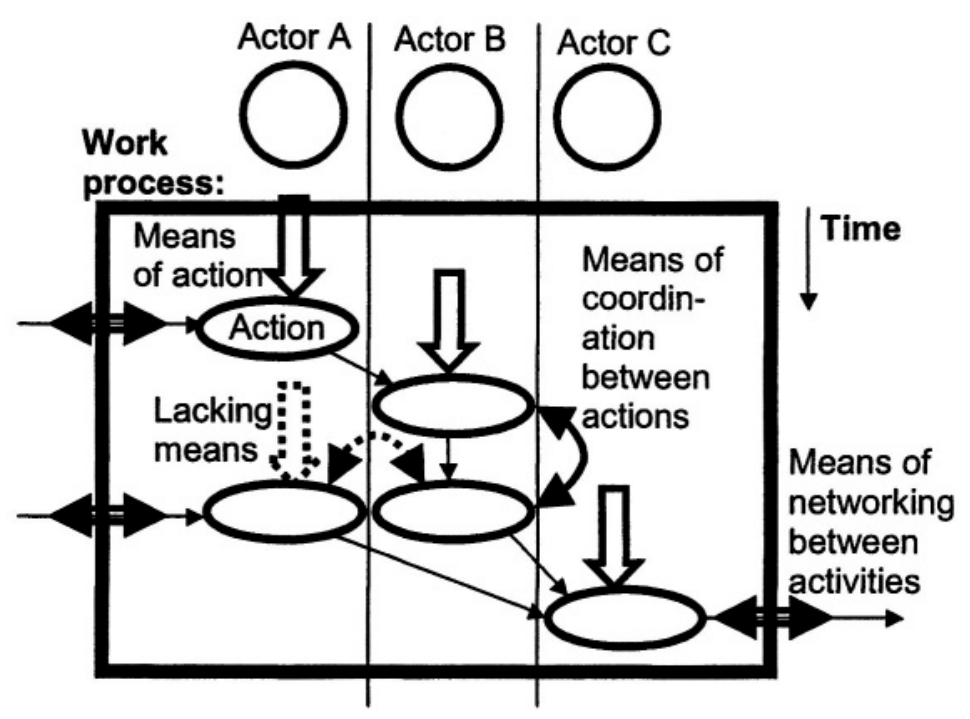

Figure 5. Zooming in from ActAD to UML 
3. The requirements specifications of each piece of software identified in the previous step are then generated utilizing the architecture and action descriptions. Since the specifications must be understandable to software engineers, we propose the use of UML diagrams (Fowler 2000) in this step. Thus far we have emphasized component diagrams, activity diagrams, and use case diagrams (including scenarios), which we use in our method in the implementation, testing, and introduction phases. The derivation of class diagrams from the Act AD framework needs further research.

\section{DISCUSSION: CHALLENGES AHEAD}

In this section we will first assess activity theory in general and the ActAD framework in particular against the objectives we set at the end of section 2. We will then evaluate the application experience thus far. At the end we shall discuss what remains to be done if activity theory is to fulfil the promises that were put forward in 1991.

\subsection{Assessment of the Analytical Framework}

Comparing the ActAD framework against the seven requirements for an improved analytical framework stated at the end of section 2, some of the requirements are met by the very theoretical approach behind it. That is, activity theory is based on the position that activities are real-life entities that abound in work practice and other domains of life, and this position is based on a century-long tradition of theoretical work, not just speculation (requirement number 5). The systemic nature of activity and its substructure of actions are specifically emphasized in the Leontievian branch of the activity theory and further developed by Engeström (requirement number 1). However, Engeström's (1987) argumentation about the origins of the structure of activity is not backed up by evidence, and we have replaced it by a more straightforward linkage to Vygotsky's and Leontiev's work.

Engeström's original framework binds the individual, collective, and technological aspects of work together (requirement number 2 and number 3 ), and we have further elaborated on this by first clarifying the presence of several individual actors and actions within a collective activity and second by identifying three different types of mediating artefacts (means of work/action, means of coordination and communication, means of networking). Unlike Engeström, we have emphasized that wider societal contexts of activities should be studied by other social theories. In practice, we have included organizational boundaries and financial relations in the analysis when relevant (requirement number 4). We regard these modifications to Engeström's developmental work research framework as our main theoretical and methodological contribution thus far.

Developmental work research has proved to be a particularly suitable approach to holistic development of work by its actors, in addition to the approach's descriptive power (requirement number 6). Several dozen successful work development projects have been undertaken, particularly in Finland, using different variants of the methodology. ActAD does not add major new methodological innovation to this body of experience, but is a more readily comprehensible representation for nonexperts than the original triangles. 
Finally, requirement number 7 states that IS frameworks should be applicable to developing technologies in the same way as to developing the other aspects of activities. In this respect, ActAD takes some steps forward from other activity-theoretical approaches by identifying the three different classes of mediating artefacts, as well as by indicating how the process of "object-transforms-into-outcome" is made up ofactions by individuals. We have suggested that actions that utilize IT can be equated with use cases, which are requirements descriptions understood by software engineers (Korpela et al. 2001a). However, this aspect of the framework is still not sufficiently developed for information systems practitioners to use it as an everyday requirements specification method. The explorative method described in section 4.3 is the first practical step in this direction.

The three types of IT-based means identified in ActAD are studied by three different design-oriented subdisciplines. As Grudin (1994) has pointed out, the means of work in individual actions is the focus of human-computer interaction (HCI) studies, while the means of coordination and communication between actors in an activity are the focus of computer-supported cooperative work (CSCW), and the means of networking between activities are mainly studied in information systems (IS/MIS). However, the scopes overlap. From the viewpoint of supporting work activities by IT, all three types of means are needed and therefore HCI, CSCW, and IS viewpoints should be considered in most developmental endeavors. Each viewpoint will require its own type of further development of the activity-theoretical analytical methods into methods for practical design.

\subsection{Assessment of the Application Experience}

There are a number of ways in which a genuinely practical theory can be applied to the IS domain (Korpela et al. 2000).

1. People participating in any activity can analyze their own activity and identify requirements for new IT-based means that facilitate their work (a shopping list for new software).

2. An IS professional can analyze any otherperson's work and identify requirements for new IT-based products that can be developed to facilitate a class of activities at a number of customer sites (a blueprint for a software product).

3. IS professionals, like any other people, can analyze their own IS development and maintenance activities and identify requirements for new methods and practices (means) for IS development (a shopping list for new methods).

4. IS researchers can analyze IS practitioners'work activities and identify requirements for more appropriate theories, methods, and education to facilitate the IS practitioners' work in general (a blueprint for relevant education).

5. IS researchers, like any other people, can analyze their own activities of IS research and education and identify requirements for better theoretical and methodological means for IS (a shopping list for new theories, frameworks and research methods).

In the cases described in section 4, the emphasis has been on the first (section 4.2), second (section 4.3), and fourth (section 4.1) types of application. As mentioned in the previous section, the use of activity theory by information systems practitioners 
(application type 2) has mainly been descriptive in nature, without a clear transition to a constructive mode by software engineers.

The most challenging way of applying Activity theory would be a combination of types 3 and 4: collaborative action research by information systems practitioners and researchers on what are the most pressing tensions, imbalances, or contradictions in every-day IS practice today, and what kind of new means might be required to address these developmental challenges. This type of action research has been conducted far too seldom, the Danish MARS and MUST projects and the software process improvement tradition being the main exceptions. We argue that activity theory and the developmental work research methods would be exceptionally helpful for information systems practitioners; they could reflect on their own work development needs, if they have first tried the same methods for analyzing other people's needs. The activity concepts would provide for a common language for practitioners and action researchers. The next major step on our research agenda is to proceed to such collaborative IS activity analysis and development. However, few software or consulting companies are ready to invest their resources in developing their work practices.

We have seen no signs of IS researchers' serious analysis of their own work activities (type 5). Maybe it is too bizarre an idea to study oneself by one's own frameworks.

\subsection{What Needs to Be Done}

The discussion above leads to the conclusion that activity theory in general and the ActAD framework in particular have a great methodological potential for IS research and practice, but this potential is still largely not realized; activity theory in IS is not a dead horse, but maybe a sleeping one. What should be done to bridge the gap between the promise and the reality?

Since we are discussing an emancipatory, developmental approach, the crucial issue is whether the methodology is suitable for practical application in everyday situations, and whether it proceeds from descriptive to constructive uses (developing new organizational information systems and possibly new software artefacts). If the activitytheoretical methodologies in IS will not meet these criteria, they will remain marginal or die away. However, even excellent methodologies do not spread by themselves but need to be accompanied by educational efforts.

We propose that the following tasks are necessary to make activity theory deliver in IS as a constructive method and not only as a descriptive method:

1. The generic concepts, frameworks, and methodologies of activity theory need to be better applied and operationalized to IS. That is, versions of activity analysis frameworks are needed which are specifically tailored to information systems analysis and development, paying attention to information flows and IT-based means, without losing the holistic view. We need activity-based methods for IS requirements analysis projects and for IS implementation projects. Furthermore, we need activity-based methods that bridge IS analysis with software development—from activity analysis and development through action case modeling to use 
cases and conceptual models. The methods and sample case descriptions need to be distributed as a "cookbook on activity theory in IS" to make them easily available to practitioners, and in order for them to be used in IS education. Besides the experience based on ActAD, various other approaches including developmental work research, change laboratory, work system method, participatory design, and ethnomethodology should be reviewed for the cookbook.

2. The most appropriate way of developing such applied methods is through collaborative action research in real-life information systems work: IS practitioners developing their own work through activity analysis and development with researcher participation. This ensures that the methods to be developed will be truly practical, something emerging from pressing needs within information systems work.

3. The wider societal and organizational contexts of activities need to be better incorporated into the analytical framework, especially as far as issues like sustainability, affordability, and socio-economic impact of information systems are concerned.

4. Finally, true theoretical discussion is required to strengthen the socio-scientific basis of the frameworks and methodologies. It is not sufficient to simply apply Engeström's triangles or our ovals as such.

\section{CONCLUSION}

The conference's call for papers challenged authors to address issues such as "Is theory irrelevant? Can theory inform practice?" In this paper we argued that the currently dominant methods in IS are not satisfactory for emancipatory research and development whose starting point is work. We reviewed the experience in applying activity theory in the field of IS, and concluded that the potential identified in it already a decade ago has not fully materialized. As our own contribution toward making activity theory more operational in IS, we presented the ActAD framework, distinguished its differences from Engeström's original model, and reviewed our experience in applying the framework to descriptive research, practical analysis, and constructive research. We claimed that in order to fully unleash the potential of activity theory, activity-based methods should be further developed for IS requirements analysis projects and IS implementation projects, as well as for facilitating software development.

We regard that activity theory has the necessary elements for becoming a relevant theory that can inform practice in IS. The task ahead is to transform the generic frameworks into genuinely practical research and development methodologies. ActAD is one step forward and so far our experiences are encouraging. However, further steps are needed. While the strong theoretical foundation provides rigor, the degree of relevance can be increased by borrowing from participatory design, ethnomethodology, and software engineering.

\section{ACKNOWLEDGEMENTS}

The paper is based on a research funded by the Academy of Finland through the INDEHELA-Methods project no. 39187 in 1998-2001 and INDEHELA-Context no. 201397 in 
2003, as well as on a research funded by the National Technology Agency Tekes through the PlugIT project no. 40246/02 and 90/03 in 2001-2004.

\section{REFERENCES}

Alter, S. "A General, Yet Useful Theory of Information Systems," Communications of the AIS (1:13), 1999, pp. 1-69.

Alter, S. "Which Life Cycle: Work System, Information System, or Software?," Communications of the AIS (7:17), 2001, pp. 1-53.

Alter, S. "The Work System Method for Understanding Information Systems and Information System Research," Communications of the AIS (9), 2002, pp. 90-104.

Bardram, J. "Temporal Coordination: Of Time and Collaborative Activities at a Surgical Department," Computer Supported Cooperative Work, (9:2), 2000, pp. 157-187.

Bertelsen, O. W., and Bødker, S. "Introduction: Information Technology in Human Activity," Scandinavian Journal of Information Systems (12:1), 2000, pp. 3-14.

Bødker, S. "Activity Theory as a Challenge to Systems Design," in H-E. Nissen, H. K. Klein and R. Hirscheim (Eds.), Information Systems Research: Contemporary Approaches and Emergent Traditions, Amsterdam: North-Holland, Amsterdam, 1991, pp. 551-564.

Bødker, S. "Computers in Mediated Human Activity," Mind, Culture, and Activity (4:3), 1997, pp. 149-158.

Engeström, Y. "Activity Theory and Individual and Social Transformation," in Y. Engeström, R. Miettinen and R. Punamäki (Eds.), Perspectives on Activity Theory, Cambridge, England: Cambridge University Press, UK, 1999, pp. 19-38.

Engeström, Y. Learning by Expanding: An Activity-Theoretical Approach to Developmental Research, Helsinki: Orienta-Konsultit, 1987.

Fowler, M. UML Distilled: A Brief Guide to the Standard Object Modeling Language, Reading, MA: Addison-Wesley, 2000.

Grudin, J. "Groupware and Social Dynamics: Eight Challenges for Developers," Communications of the $\operatorname{ACM}(37: 1), 1994$, pp. 92-105.

Hedegaard, M.; Chaiklin, S.; and Jensen, U. J. "Activity Theory and Social Practice: An Introduction," in S. Chaiklin, M. Hedegaard and U. J. Jensen (Eds.), Activity Theory and Social Practice: Cultural-Historical Approaches, Aarhus, Denmark: Aarhus University Press, 1999, pp. 12-30.

Häkkinen, H. "Rapid Method for Integration Requirements Assessment: Case Maternity Care," in S. Laukkanen and S. Sarpola (Eds.), Electronic Proceedings of the 26th Information Systems Research Seminar in Scandinavia, Helsinki School of Economics, Helsinki, 2003.

Iivari, J., and Lyytinen, K. "Research on Information Systems Development in Scandinavia: Unity in Plurality," Scandinavian Journal of Information Systems (10:1/2), 1998, pp. 135185.

Kensing, F., and Blomberg, J. "Participatory Design: Issues and Concerns," Computer Supported Cooperative Work (7:3/4), 1998, pp. 167-185.

Korpela, M.; Eerola, A.; Mursu, A.; and Soriyan, H. A. "Use Cases as Actions Within Activities: Bridging the Gap Between Information Systems Development and Software Engineering," abstract, in Proceedings of the Second Nordic-Baltic Conference on Activity Theory and Sociocultural Research, Ronneby, Sweden, 2001a, p. 51.

Korpela, M.; Mursu, A.; and Soriyan, H. A. "Two Times Four Integrative Levels of Analysis: A Framework," in N. L. Russo, B. Fitzgerald and J. I. DeGross (Eds.), Realigning Research and Practice in Information Systems Development: The Social and Organizational Perspective, Boston: Kluwer Academic, 2001b, pp. 367-377. 
Korpela, M.; Mursu, A.; Soriyan, H. A.; and Eerola, A. "Information Systems Research and Information Systems Practice in a Network of Activities," in Y. Dittrich , C. Floyd, and R. Klischewski (Eds.), Social Thinking-Software Practice, Cambridge, MA: MIT Press, 2002a, pp. 287-308.

Korpela, M.; Mursu, A.; Soriyan, H. A.; and Olufokunbi, K. C. "Information Systems Development as an Activity," Computer Supported Cooperative Work (11:1/2), 2002b, pp. 111-128.

Korpela, M.; Soriyan, H. A.; and Olufokunbi, K. C. "Activity Analysis as a Method for Information Systems Development: General Introduction and Experiments from Nigeria and Finland," Scandinavian Journal of Information Systems (12:1), 2000, pp. 191-210.

Kuutti, K. "Activity Theory and its Applications to Information Systems Research and Development," in H-E. Nissen, H. K. Klein and R. Hirschheim (Eds.), Information Systems Research: Contemporary Approaches and Emergent Traditions, Amsterdam: NorthHolland, 1991, pp. 529-549.

Leontiev, A. N. Activity, Consciousness and Personality, Englewood Cliffs, NJ: Prentice-Hall, 1978.

Mursu, A.; Soriyan, A.; and Korpela, M. "ICT for Development: Sustainable Systems for Local Needs," in-progress research paper presented at the IFIP TC8 \& TC9/WG8.2 \& WG9.4 Joint Working Conference on Information Systems Perspectives and Challenges in the Context of Globalization, Athens University of Economics and Business, Athens, 2003.

Mursu, A.; Soriyan, H. A.; and Korpela, M. "Risky Business: A Case Study on Information Systems Development in Nigeria," in S. Krishna and S. Madon (Eds.), Information and Communication Technologies and Development: New Opportunities, Perspectives and Challenges, Bangalore: Indian Institute of Management, 2002, pp. 385-401.

Mwanza, D. Towards an Activity-Oriented Design Methodfor HCI Research and Practice, Unpublished Ph.D. Thesis, Open University, Milton Keynes, UK, 2002 (available online at http://iet.open.ac.uk/pp/d.mwanza/Phd.htm).

Myers, M. D. "Investigating Information Systems with Ethnographic Research," Communication of the AIS (2:23), 1999, pp. 1-20.

Orlikowski, W. J., and Baroudi, J. J. "Studying Information Technology in Organizations: Research Approaches and Assumptions," Information Systems Research (2), 1991, pp. 1 -28.

Redmiles,D. "Introduction," Computer Supported Cooperative Work: Special Issue on Activity Theory (11:1/2), 2002, pp. 1-11.

Robertson, S., and Robertson, R. Mastering the Requirements Process, Reading, MA: AddisonWesley, 1999.

Soriyan, H. A. A Conceptual Framework for Improved Information Systems Development Methodology, Unpublished Ph.D. Thesis, Obafemi Awolowo University, Ile-Ife, Nigeria, 2004.

Toivanen, M.; Eerola, A.; and Korpela, M. "From Information Systems Requirements to Software Components: Home Care Case," in S. Laukkanen and S. Sarpola (Eds.), Electronic Proceedings of the 26th Information Systems Research Seminar in Scandinavia, Helsinki School of Economics, Helsinki, 2003.

Vrazalic, L., and Gould, E. "Towards an Activity-Based Usability Evaluation Methodology," in M. Anders, A. Opdahl, and S. Bjørnstad (Eds.) Electronic Proceedings of 24th Information Systems Research Seminar in Scandinavia, 2001.

Vygotsky, L. S. Mind in Society: The Development of Higher Psychological Processes, M. Cole. V. John-Steiner, and S. Schribner (Eds.), Boston: Harvard University Press, 1978.

Walsham, G. "Actor-Network Theory and IS Research: Current Status and Future Prospects," in A. S. Lee, J. Liebenau and J. I. DeGross (Eds.), Information Systems and Qualitative Research, London: Chapman \& Hall, 1997, pp. 466-480.

Walsham, G., and Han, C-K. "Structuration Theory and Information Systems Research.” Journal of Applied Systems (17), 1991, pp. 77-85. 


\section{ABOUT THE AUTHORS}

Mikko Korpela is Research Director of the Healthcare Information Systems R\&D Unit, University of Kuopio, Finland, and a decent at the Department of Computer Science at the same university. He achieved his D.Tech. degree in Information Systems at the Helsinki University of Technology in 1994. He is a member of IFIP WG 8.2 and 9.4. His research interests include West African political history, activity development, and information systems development particularly in healthcare. Mikko can be reached by e-mail at mikko.korpela@uku.fi.

Anja Mursu is an acting professor of Software Engineering at the Department ofComputer Science, University of Kuopio, Finland. She achieved her Ph.D. in Information Systems in 2002 at the University of Jyväskylä, Finland. Her research interests include information systems development, especially in developing countries, risk assessment, sustainability of information systems, activity theory, and recently also usability of information systems. Anja can be reached by e-mail at anja.mursu@uku.fi.

Abimbola Soriyan is a lecturer at the Computer Science and Engineering Department, Obafemi Awolowo University, Ile-Ife, Nigeria. She achieved her Ph.D. on information systems development in Nigerian software industry at the same university in 2004. Her research interests include information systems development with emphasis on healthcare. In particular, she is interested in why many developing countries have not embraced IT despite the success stories in the West. Abimbola can be reached by e-mail at hasoriyan@yahoo.com.

Anne Eerola is a professor in Software Engineering at the Department of Computer Science, University of Kuopio, Finland. She achieved her Ph.D. degree in 1994 at the same university on the analysis, design and maintenance of object oriented systems. She has worked for 10 years in the software industry and another 10 years as a teacher in the university. Her research emphasizes requirements modeling, software architectures and components, design patterns, and software testing. Anne can be reached by e-mail at anne.eerola@cs.uku.fi.

Heidi Häkkinen, R.N., is a Health Informatics student at the Department of Health Policy and Management, University of Kuopio, Finland. She has been working in the field of clinical information systems for the past six years. Currently she works for a research project in health care systems integration and can be reached at heidi.hakkinen@uku.fi.

Marika Toivanen is a Ph.D. student at the Department of Computer Science, University of Kuopio, Finland. She did her Master's thesis about human factors in software processes in 2002. Since then, she has been studying information systems development methods. Currently she focuses on eliciting methods of health care systems requirements. Marika can be reached at marika.toivanen@uku.fi. 